\title{
Standing Committee on Epidemiology and Health Services Research
}

Report to the General Assembly in Stockholm, June 2002

\section{Workshop}

At the last annual EULAR congress in Prague the standing committee organised a second workshop on measurement issues. The first workshop took place at the first annual congress in Nice. The meeting was well attended and very much appreciated. Therefore, it was decided to offer a third workshop at this year's congress. During the congress an interactive session on behalf of the standing committee was provided by Professor Maarten Boers (Department of Clinical Epidemiology at the Free University, Amsterdam) and Robert Landewé (Department of Internal Medicine, Division of Rheumatology, University of Maastricht, Maastricht). The topic was design and analysis of a randomised clinical trial (RCT).

\section{Multicountry prevalence study}

A major undertaking of this standing committee is the multicountry prevalence study to detect cases of rheumatoid arthritis and spondyloarthritis. The study consists of two phases. Phase I-in which screening by telephone interview is the core activity-is financially supported by EULAR. Professor Francis Guillemin from Nancy, France is the leading person for all these activities. A full report was given at the meeting

Phase 1 of the EULAR prevalence survey is directed at developing a questionnaire, suitable for telephone administra- tion by lay people, for the detection of cases of rheumatoid arthritis and spondyloarthritis in general population surveys.

The Stockholm June 2002 intermediate study committee reported that currently nine countries (10 areas) are taking part. After adaptation of candidate questions into their own language, each centre has conducted interviewer recruitment among volunteering patients. They are in the process of testing this battery of questions in four categories of subjects: patients with rheumatoid arthritis, patients with spondyloarthritis, outpatient controls, and a random sample of controls from the general population (50 people in each category contacted by phone in each area). Data will be analysed to select questions relevant to each country to convey diagnosis sensitivity and specificity in the best way possible.

Phase 2 of the survey will then be the field implementation of the prevalence survey with this international questionnaire in each participating country.

\section{Clinical epidemiology}

In October 2001 a five day course on clinical epidemiology including clinical trials and selected topics took place in Bucharest, Romania, in collaboration with the Standing Committee on Education and Training (Professor Tony Woolf) and the Standing Committee for International Clinical Studies Including
Therapeutic Trials (Professor Piet van Riel). The course was financially supported by EULAR and primarily intended for young rheumatologists from eastern European countries. Altogether 43 rheumatologists and five tutors participated in the interactive workshops. Issues covered included pre- and posttest assessment, critical appraisal of the literature and basic epidemiological concepts such as prevalence, incidence, relative risk, odds ratio, number needed to treat, sensitivity, specificity, predictive value, likelihood ratio, design and analysis of a randomised clinical trial, sensitivity to change, standardised response mean, effect size, and so on. Practical exercises were frequently included. A full evaluation of the course showed that it was very much appreciated. The executive board of EULAR has approved a repeat of the course in 2004.

\section{Further comments}

The standing committee is exploring whether an $e$-journal club among interested members would be feasible and affordable. Critical appraisal of the rheumatological literature would be the focus of any such activities.

At next year's annual congress in Lisbon professor Francis Guillemin will be proposed to the EULAR executive board as the next chairman of this standing committee.

Finally, we are interested in co-opting colleagues who would like to contribute to the activities of the committee.

$S$ van der Linden sli@ms-azm-3.azm.nl 